\title{
Older versus younger patients with metastatic adenocarcinoma of the esophagus, gastroesophageal junction, and stomach: A pooled analysis of eight consecutive North Central Cancer Treatment Group (NCCTG) trials
}

\author{
AMINAH JATOI ${ }^{1}$, NATHAN R. FOSTER ${ }^{1}$, JAMES R. EGNER ${ }^{2}$, PATRICK A. BURCH ${ }^{1}$, \\ PHILIP J. STELLA ${ }^{3}$, JOSEPH RUBIN ${ }^{1}$, SHAKER R. DAKHIL ${ }^{4}$, DANIEL J. SARGENT ${ }^{1}$, \\ BRIAN R. MURPHY ${ }^{5}$ and STEVEN R. ALBERTS ${ }^{1}$
}

\author{
${ }^{1}$ Mayo Clinic Rochester, Rochester, MN 55905; ${ }^{2}$ Carle Cancer Center CCOP, Urban, IL 61801; ${ }^{3}$ Michigan Cancer \\ Research Consortium, Ann Arbor, MI 48106; ${ }^{4}$ Wichita Community Clinical Oncology Program, Wichita, \\ KS 67214-3882; ${ }^{5}$ Toledo Community Hospital Oncology Program CCOP, Toledo, OH 43623, USA
}

Received February 6, 2009; Accepted March 30, 2009

DOI: 10.3892/ijo_00000535

\begin{abstract}
Whether elderly patients with metastatic esophageal, gastroesophageal, and gastric cancer do as well with chemotherapy as their younger counterparts was investigated in this pooled analysis. In total, 367 patients from 8 consecutive, first-line trials were included: i) etoposide + cisplatin; ii) 5-fluorourucil + leucovorin; iii) 5fluorouracil + levamisole; iv) irinotecan; v) docetaxel + irinotecan; vi) oxaliplatin + capecitabine; vii) docetaxel + capecitabine; and viii) bortezomib + paclitaxel + carboplatin. One hundred and fifty-four $(42 \%)$ patients were $\geq 65$ years old (range: 65-86), and 213 younger (range: 20-64). Elderly patients had worse performance scores (2-3): 19 vs. $8 \%$ $(\mathrm{p}<0.0001)$. Rates of grade $3+$ adverse events across all chemotherapy cycles in univariate and multivariate analyses (adjusted for gender, performance score, and stratified by individual study) were higher among elderly patients. Rates of neutropenia, fatigue, infection, and stomatitis in elderly vs. younger patients were 31 vs. $29 \%$ ( $\mathrm{p}=0.02$ by multivariate analyses); 15 vs. $5 \%$ ( $\mathrm{p}=0.01) ; 9$ vs. $4 \%(\mathrm{p}=0.03) ; 6$ vs. $1 \%(\mathrm{p}=0.04)$. In contrast, duration of chemotherapy, overall survival, and progression-free survival were comparable. Although age should not preclude trial entry, these adverse event rates suggest a need to develop more tolerable regimens for older patients with these malignancies.
\end{abstract}

Correspondence to: Dr Aminah Jatoi, Mayo Clinic Rochester, 200 First Street SW, Rochester, MN 55905, USA

E-mail: jatoi.aminah@mayo.edu

Key words: esophageal cancer, elderly, chemotherapy, adverse events

\section{Introduction}

Cancer occurs predominantly in older patients (1). The demographics surrounding esophageal, gastroesophageal, and gastric cancer offer no exception to this observation. These cancers occur predominantly in patients who are older than 65 years of age (2), and, over time, the age-specific incidence of these malignancies has shifted towards the elderly (2).

Thus, it becomes increasingly more important to understand how best to treat elderly patients who develop adenocarcinoma of the esophagus, gastroesophageal junction, and stomach. The majority of previous studies in patients with these malignancies has examined age-based outcomes in surgical patients and in those receiving other forms of potentially curative therapy; but scant attention has been given to patients with metastatic disease (3-9). Focusing on this latter group is relevant because most patients diagnosed with these malignancies are found to have metastatic cancer either at diagnosis or at some point in their lives.

In other cancer settings, elderly patients appear to derive comparable therapeutic outcomes from chemotherapy in exchange for higher rates of severe adverse events. In patients with lung cancer, breast cancer and other gastrointestinal cancers, elderly chemotherapy-treated patients suffer higher rates of severe myelosuppression, bleeding, nausea, and fatigue (10-12). Fewer such comparative studies have been conducted in patients with metastatic esophageal, gastroesophageal, and gastric cancer.

Do such age-based differences in adverse events also occur in patients receiving first-line chemotherapy for these malignancies? The present study was undertaken to answer this question. Utilizing data from eight consecutive phase II trials, we sought to determine differences in adverse events and other outcomes in older and younger patients with metastatic esophageal, gastroesophageal, and gastric cancer. 


\section{Materials and methods}

Overview. The present study was reviewed and approved by the Mayo Clinic Institutional Review Board (IRB). In addition, all eight of the NCCTG trials included in this study had individually received IRB approval from the multiple other institutions that had participated in patient accrual.

These eight studies were chosen because they comprise all the NCCTG trials conducted in patients with metastatic adenocarcinoma of the esophagus, gastroesophageal junction, and stomach over the past 20 years within this National Cancer Institute-funded, multi-institutional cancer cooperative group.

All were first-line, phase II studies that tested the following regimens for the following indications (Table I): i) etoposide and cisplatin for metastatic gastric cancer (NCCTG 874151); ii) 5-fluorouracil and leucovorin for metastatic gastric cancer (NCCTG 884801); iii) 5-fluorouracil and levamisole for metastatic gastric cancer (NCCTG 914151); iv) irinotecan for metastatic esophagogastric junction or gastric cancer (NCCTG 964152); v) irinotecan and docetaxel for metastatic lower esophageal, gastroesophageal, and gastric cardia cancer (NCCTG N9941); vi) oxaliplatin and capecitabine for metastatic lower esophageal, gastroesophageal, and gastric cardia cancer (NCCTG N0149); vii) docetaxel and capecitabine for metastatic adenocarcinoma of the gastroesophageal junction and stomach (NCCTG N0242); and viii) bortezomib, carboplatin, and paclitaxel for metastatic adenocarcinoma of the lower esophageal, gastroesophageal junction, and stomach (NCCTG N044B).

Age cutoffs. The primary goal of the present study was to compare differences in adverse events in patients $\geq 65$ years vs. those $<65$. This age cutoff was chosen a priori for two reasons. First, it defines 'elderly' throughout a large portion of the epidemiological literature (13). Second, the United States Census Bureau and the United States Medicare policy also utilize this cutoff in their definition of 'elderly' (14). Because other cancer cooperative groups have utilized $\geq 70$ years, a secondary set of analyses were performed with this other age cutoff.

Definition of end-points and statistics. The primary end-point of the present study was to compare the rates of grade 3 or worse adverse events, as defined by the Common Terminology Criteria (CTC), versions $1-3$, in patients who were $\geq 65$ years of age vs. younger. Four studies had used CTC version 1, three CTC version 2, and one CTC version 3. However, the same criteria were used consistently within each study, and criteria for each adverse event were easily translatable across trials. Non-hematologic adverse event data consisted only of those thought to be related to cancer therapy, but, in contrast, all hematologic adverse events were attributed to cancer therapy. A sample size of 362 patients enabled the study team to detect a $15 \%$ difference in the rate of grade 3 or worse adverse events, for example, from 40 to $55 \%$, with a 2-sided significance level of 0.05 and $80 \%$ power.

Before pooling adverse event data, the Breslow-Day test was used to confirm the homogeneity of the adverse events from these 8 studies $(\mathrm{p}=0.74)$. Then univariate and multivariate logistic regression models, stratified by individual study, were used to assess whether age was predictive of adverse events in the pooled data set. The score and likelihood ratio test $\mathrm{p}$-values were used to test the significance of age in these respective models.

$\chi^{2}$ or Fisher's exact tests were used to test for an association between age and categorical variables, such as gender and performance score. The Wilcoxan rank-sum test was used to look for an association between age and the continuous variable of interest.

Overall survival and cancer progression-free survival were calculated from date of study registration to death or date of study registration to lack of cancer progression/death, respectively. When the dates of death or cancer progression were unknown, data were censored on the date of last followup. Survival data were censored at 3 years. Again, prior to pooling data across studies, the homogeneity assumption was tested for age with the cutoffs of 65 and 70 years by using the likelihood ratio test $\mathrm{p}$-value for the individual study by age interaction from a Cox regression model. Because pooling was appropriate, only the pooled estimates are shown.

Univariate and multivariate Cox proportional hazards models were used to explore the association of age to overall survival and cancer progression-free survival. The score and likelihood ratio test $\mathrm{p}$-values were used to test the significance of age in the covariate in the univariate and multivariate models, respectively. Graphical and statistical methods were used to examine whether the underlying model assumptions were satisfied.

All statistical tests were 2-sided. A p $<0.05$ is considered statistically significant. Statistical analyses were performed with SAS (SAS Institute, Cary, NC, USA).

\section{Results}

Baseline demographics. A total of 367 patients were included in this pooled analysis, and adverse event data were available in 362. The median age of the entire cohort was 61 years (range: $20-86)$. A total of 154 patients $(42 \%)$ were $\geq 65$ years, and $92(25 \%)$ were $\geq 70$ years of age. The majority, 318 $(87 \%)$, were men. Eastern Cooperative Oncology Group (ECOG) performance scores of $0,1,2$, and 3 were observed at study entry in $39,49,11$, and $1 \%$ of patients, respectively. Information on the primary tumor location had not been acquired in $13 \%$ of the cohort, but in the remaining cohort it consisted of esophagus, esophagogastric junction, and stomach in 4, 33 and $50 \%$ of patients, respectively.

Baseline demographics revealed differences in performance score based on age (Table II). Patients who were $\geq 65$ years had worse performance scores. Scores of 0, 1, and 2-3 were observed in 25, 56 and $19 \%$, respectively, for elderly patients in contrast to 49,44 and $8 \%$ for younger patients, respectively $(\mathrm{p}<0.0001)$. Similar such differences were observed with an age cutoff of 70 years (Table III).

Duration of chemotherapy. All studies required that patients remain on chemotherapy until cancer progression, especially severe adverse events, or a general decline in patient status. Among the age-defined groups, there were only slight differences in duration of chemotherapy. For patients $\geq 65$ years of age, the mean time on chemotherapy was 3.3 months (standard 
Table I. Clinical trials in this pooled analysis.

\begin{tabular}{|c|c|c|}
\hline Authors/(ref.) & $\mathrm{N}$ & Regimen \\
\hline Elliott, et al (19) & 48 & $\begin{array}{l}\text { Etoposide } 130 \mathrm{mg} / \mathrm{m}^{2} / \text { day intravenously x } 3 \text { days }+ \text { cisplatin } \\
45 \mathrm{mg} / \mathrm{m}^{2} / \text { day intravenously days } 2 \text { and } 3 \text { (cycle length }=28 \text { days) }\end{array}$ \\
\hline Rubin, et al (20) & 42 & $\begin{array}{l}5 \text {-fluorouracil } 425 \mathrm{mg} / \mathrm{m}^{2} \text { intravenously days } 1-5+\text { leucovorin } \\
\left.20 \mathrm{mg} / \mathrm{m}^{2} \text { intravenously days } 1-5 \text { (cycle length }=28 \text { days }\right)\end{array}$ \\
\hline Burch, et al (21) & 44 & $\begin{array}{l}\text { 5-fluorouracil } 450 \mathrm{mg} / \mathrm{m}^{2} \text { intravenously days } 1-5+\text { levamisole } 100 \mathrm{mg} / \mathrm{m}^{2} \text { orally } 3 \text { times a day, } \\
\text { days } 1-3 \text { and } 50 \mathrm{mg} / \mathrm{m}^{2} \text { orally } 3 \text { times a day on days } 4 \text { and } 5 \text { (cycle length }=35 \text { days) }\end{array}$ \\
\hline Erlichman, et al (22) & 68 & Irinotecan $260-320 \mathrm{mg} / \mathrm{m}^{2}$ intravenously on day 1 (cycle length $=21$ days) \\
\hline Jatoi, et al (23) & 46 & $\begin{array}{l}\text { Docetaxel } 50 \mathrm{mg} / \mathrm{m}^{2} \text { intravenously on day } 1+\text { irinotecan } \\
130 \mathrm{mg} / \mathrm{m}^{2} \text { intravenously on day } 1 \text { (cycle length } 21 \text { days) }\end{array}$ \\
\hline Jatoi, et al (24) & 43 & $\begin{array}{l}\text { Oxaliplatin } 130 \mathrm{mg} / \mathrm{m}^{2} \text { intravenously on day } 1+\text { capecitabine } \\
850-1000 \mathrm{mg} / \mathrm{m}^{2} \text { orally twice a day x } 14 \text { days }(\text { cycle length }=21 \text { days) }\end{array}$ \\
\hline Giordano, et al (25) & 44 & $\begin{array}{l}\text { Docetaxel } 75 \mathrm{mg} / \mathrm{m}^{2} \text { intravenously on day } 1+\text { capecitabine } \\
825 \mathrm{mg} / \mathrm{m}^{2} \text { orally twice a day on days } 1-14(\text { cycle length }=21 \text { days })\end{array}$ \\
\hline Jatoi, et al (26) & 35 & $\begin{array}{l}\text { Bortezomib } 1.2 \mathrm{mg} / \mathrm{m}^{2} \text { intravenously on days } 1,4 \text { and } 8+\text { paclitaxel } \\
175 \mathrm{mg} / \mathrm{m}^{2} \text { intravenously on day } 2+\text { carboplatin area under } \\
\text { the curve of } 2 \text { intravenously on day } 2 \text { (cycle length }=21 \text { days) }\end{array}$ \\
\hline
\end{tabular}

Table II. Demographics based on the $\geq 65$ years of age cutoff $(\mathrm{n}=367){ }^{\mathrm{a}}$

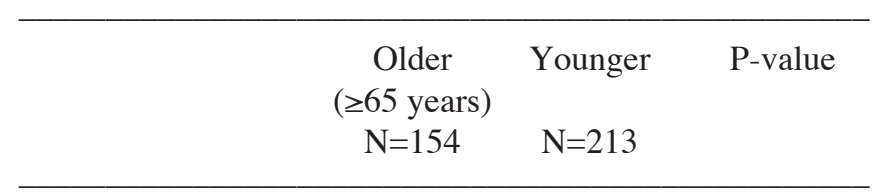

Age, median (range) $71(65,86) 54(20,64) \quad$ Not reported

Gender

$\begin{array}{lrrr}\text { Male } & 129(84) & 189(89) & 0.17 \\ \text { Female } & 25(16) & 24(11) & \end{array}$

Performance score

$\begin{array}{lrrr}0 & 39(25) & 104(49) & <0.0001 \\ 1 & 86(56) & 93(44) & \\ 2-3 & 29(19) & 16(7) & \\ \text { Tumor location }^{\mathrm{b}} & & & \\ \begin{array}{l}\text { Esophagus } \\ \text { Gastroesophageal }\end{array} & 65(34) & 75(40) & \\ \text { junction } & & & \\ \text { Stomach } & 79(61) & 103(55) & \end{array}$

${ }^{a}$ Numbers in parentheses refer to percentages, unless otherwise specified. ${ }^{b}$ Not all trials reported on tumor location.
Table III. Demographics based on the $\geq 70$ years of age cutoff $(n=367){ }^{a}$

\begin{tabular}{lccc}
\hline & $\begin{array}{c}\text { Older } \\
(\geq 70 \text { years }) \\
\mathrm{N}=92\end{array}$ & Younger & P-value \\
& & & \\
\hline Age, median (range) & & Not reported \\
Gender & & & \\
Male & $73(79)$ & $245(89)$ & \\
Female & $19(21)$ & $30(11)$ & 0.02 \\
Performance score & & & \\
0 & $22(24)$ & $121(44)$ & 0.0009 \\
1 & $52(56)$ & $127(46)$ & \\
$2-3$ & $18(20)$ & $27(10)$ & \\
Tumor location & & & \\
Esophagus & & & \\
Gastroesophageal & $25(32)$ & $95(40)$ & \\
junction & & & \\
Stomach & $49(64)$ & $133(55)$ & \\
\hline
\end{tabular}

${ }^{a}$ Numbers in parentheses refer to percentages, unless otherwise specified. ${ }^{b}$ Not all trials reported on tumor location. 
Table IV. Adverse events in patients $\geq 65$ years of age vs. younger., ${ }^{\mathrm{a}, \mathrm{b}}$

\begin{tabular}{lccc}
\hline & $\begin{array}{c}\text { Older } \\
(\geq 65 \text { years })\end{array}$ & Younger (\%) & P-value \\
\hline Neutropenia & 31 & 29 & 0.02 \\
Fatigue & 15 & 5 & 0.01 \\
Infection & 9 & 4 & 0.03 \\
Stomatitis & 6 & 1 & 0.04 \\
Hypotension & 2 & 0 & 0.04 \\
Renal failure & 2 & 0 & 0.02 \\
Dyspnea & 3 & 1 & 0.51 \\
Thrombocytopenia & 9 & 7 & 0.17 \\
Vomiting & 12 & 10 & 0.99 \\
Diarrhea & 13 & 10 & 0.39 \\
\hline
\end{tabular}

${ }^{a}$ All adverse events are grade 3 or greater unless otherwise specified. ${ }^{\mathrm{b}}$ Adverse events over all chemotherapy cycles are reported. ${ }^{\mathrm{C}} \mathrm{P}-\mathrm{values}$ are derived from logistic regression analyses, adjusted for performance score and gender and stratified by individual study; no major differing conclusions arose based on univariate analyses.

deviation: 4.1 months) in contrast to 3.4 months (standard deviation 4.0 months) for younger patients; $(\mathrm{p}=0.21)$. For patients $\geq 70$ years of age, this interval was 2.9 months (standard deviation: 4.3 months) in contrast to 3.5 months (standard deviation 4 months); $(\mathrm{p}=0.04)$. There are no available data on the use or duration of second- or third-line chemotherapy.

Adverse events. In general, $69 \%$ of all patients suffered a grade 3 or worse adverse event, $33 \%$ a grade 4 or worse event, and $2 \%$ died. Fatal adverse events were infection-related in half of patients.
A Overall survival

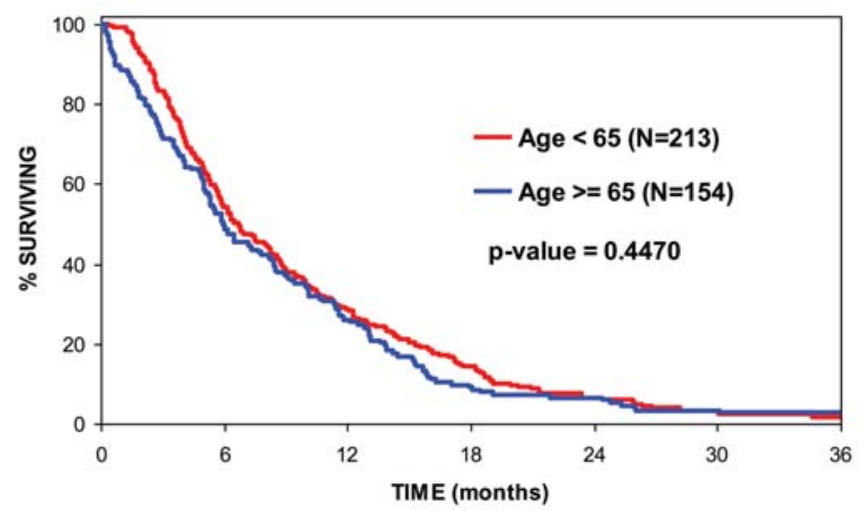

B Cancer Progression-Free Survival

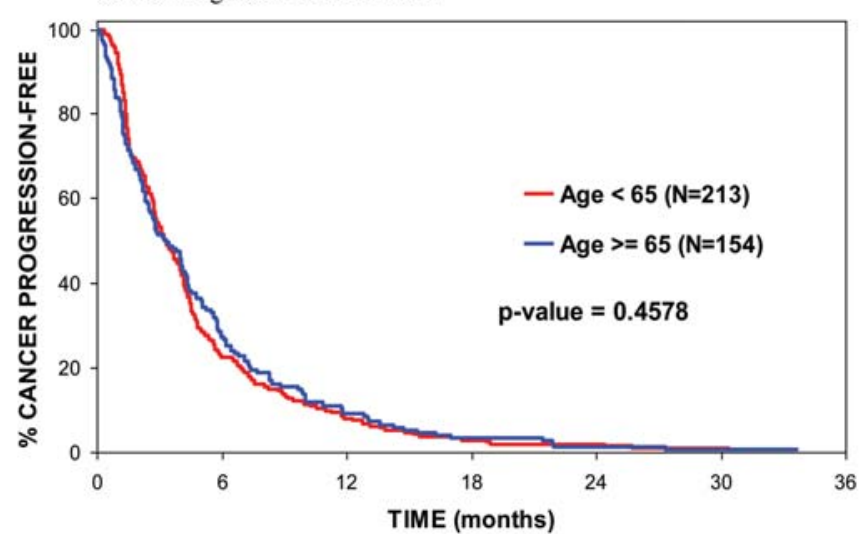

Figure 2. (A) Overall survival was not statistically different between patients who were $\geq 65$ years of age vs. younger: median survival of 6.0 months vs. 6.7 months $(\mathrm{p}=0.45$ ). (B) Cancer progression-free survival was not statistically different between patients who were $\geq 65$ years of age vs. younger: median survival of 3.3 months in both groups $(\mathrm{p}=0.46)$.

As stated earlier, the primary end-point of this study was a comparison of grade 3 or worse adverse events between patients who were $\geq 65$ years of age vs. younger patients. The

\section{Age-Based Odds Ratios for Severe Adverse Events}

\section{YOUNGER OLDER ( $\geq 65$ years) Odds Ratio}

Trial number of grade $3+$ events/total patients (\%)

$\begin{array}{lrlrl}874151 & 24 / 29 & (83) & 15 / 18(83) \\ 884801 & 9 / 22(41) & 12 / 19(63) \\ 914151 & 11 / 23 & (48) & 14 / 21(67) \\ 964152 & 20 / 34 & (59) & 22 / 31(71) \\ \text { N } 9941 & 8 / 21 & (38) & 14 / 22(64) \\ \text { N0149 } & 17 / 27 & (63) & 12 / 16(75) \\ \text { N0242 } & 27 / 32 & (84) & 9 / 12(75) \\ & & & \\ \text { Overall } & \mathbf{1 3 9 / 2 1 1} & \mathbf{( 6 6 )} & \mathbf{1 1 0 / 1 5 1}(\mathbf{7 3})\end{array}$

YOUNGER with more adverse events

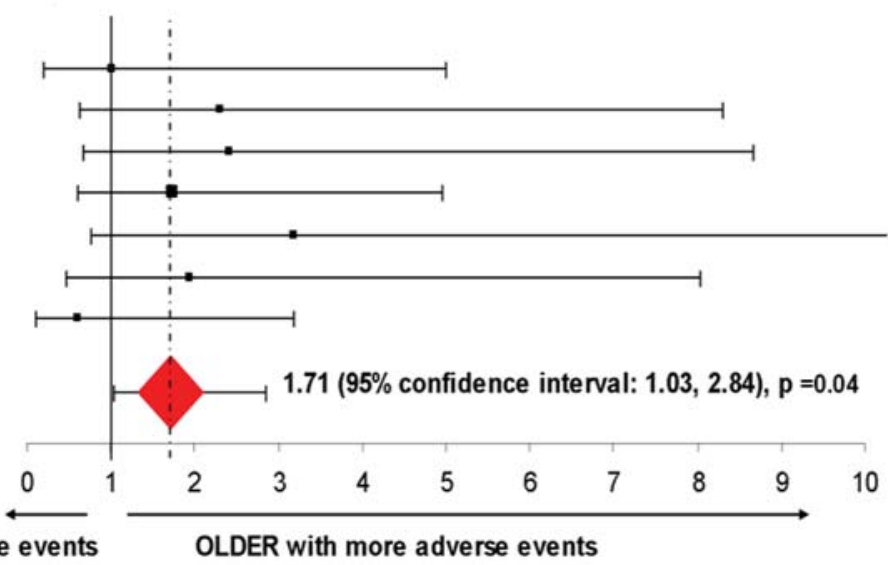

Figure 1. Odds ratios demonstrate that older patients had a significantly higher rate of severe adverse events. 
incidence of such adverse events across all chemotherapy treatment cycles was greater among older patients. Grade 3 or worse adverse events were observed in $73 \%$ of patients $\geq 65$ years of age vs. $66 \%$ of younger patients ( $\mathrm{p}=0.02$ ), and after adjustment for performance score and gender and after stratification by individual study, this difference remained statistically significant ( $\mathrm{p}=0.04)$ (Table IV).

What types of severe adverse events occurred more frequently in older patients? Rates of grade 3 or worse neutropenia, fatigue, infection, stomatitis, renal failure, and hypotension were statistically greater among patients who $\geq 65$ years of age in both univariate and multivariate analyses (Table IV and Fig. 1).

In addition, grade 4 or worse adverse events were more commonly observed in patients who were $\geq 65$ years of age compared to their younger counterparts: 40 vs. $28 \%$ ( $\mathrm{p}=0.002$ and 0.004 , in univariate and multivariate analyses, respectively). Death was also more commonly observed in elderly patients, although results were not statistically significant: 4 vs. $1 \%$ ( $p=0.05$ and 0.06 in univariate and multivariate analyses, respectively).

In patients who were $\geq 70$ years of age, grade 3 or worse adverse events occurred more commonly: 73 vs. $68 \%$, but this difference did not reach statistical significance $(\mathrm{p}=0.24$ and 0.37 in univariate and multivariate analyses, respectively). Similarly, although grade 4 or worse adverse events occurred more often in older as opposed to younger patients at 35 and $33 \%$, respectively ( $\mathrm{p}=0.39$ and 0.63 in univariate and multivariate analyses, respectively) and although grade 5 events also occurred more commonly 4 and $1.5 \%$, respectively $(\mathrm{p}=0.09$ and 0.17 in univariate and multivariate analyses, respectively), as noted, none of these differences reached statistical significance.

Overall and progression-free survival. In terms of other clinical outcomes, no notable age-related differences were observed. Overall survival was not statistically different in patients who were $\geq 65$ years of age compared to younger patients: 6.0 months median survival vs. 6.7 months $(p=0.45$ in a univariate analysis) (Fig. 2A). Moreover, cancer progressionfree survival was also not statistically different: median survival of 3.3 months in both groups ( $\mathrm{p}=0.46$ in a univariate analysis) (Fig. 2B). Multivariate models yielded similar results. Identical conclusions were generated when utilizing an age cutoff of 70 years.

\section{Discussion}

The present study focused on 8 consecutive clinical trials from the NCCTG, and a total of 367 patients were included. In evaluating differences in adverse events and other clinical outcomes in patients with metastatic adenocarcinoma of the esophagus, gastroesophageal junction, and stomach, this study provided some important age-based observations: the number and severity of adverse events were increased among elderly patients compared to their younger counterparts, but survival appeared comparable. These observations are best illustrated with an age cutoff of 65 years; diminished statistical power may explain the absence of statistically significant findings with an age cutoff of 70 years. To our knowledge, this present study represents one of the few pooled analyses to examine the ramifications of age in patients with metastatic cancer of the esophagus, gastroesophageal junction, and stomach. It underscores the importance of considering age when choosing a chemotherapy regimen for an older patient, and it suggests a need for designing age-specific chemotherapy clinical trials.

However, this study is not the first to comment on a designing tailored, age-specific therapy in patients with this group of malignancies. Al Batram and others performed a subgroup analysis of 94 patients who were treated with either a combination of 5-fluorouracil, leucovorin, and oxaliplatin or a combination of 5-fluorouracil, leucovorin, and cisplatin for metastatic gastroesophageal cancer (15). Making direct comparisons based on chemotherapy regimen among patients who were exclusively $\geq 65$ years of age, these investigators observed that the former regimen was associated with an improvement in cancer progression-free survival and lower toxicity rates. They concluded that their results 'underline the need to design and conduct trials for gastric cancer targeted specifically at older adult patients', thereby emphasizing further the implications of the present NCCTG pooled analysis.

Finally, two other points relevant to study design merit mention. First, this study included patients with esophageal cancer, gastroesophageal junction cancer, and gastric cancer. Although focusing on only one of these cancer types would have been ideal, this amalgamated approach is not unprecedented (16-18); and, clearly, to date, there has been substantial overlap in chemotherapy options for patients with these malignancies. Therefore, the approach of aggregating patients with these cancer types, as done here, can be easily justified.

Second, the elderly patients who participated in all eight of these NCCTG trials may represent a culled group of relatively fit elderly patients, as the 8 phase II trials in this pooled analysis were not specifically designed for older cancer patients. Hence, the more frequent and severe adverse events of older patients observed in this study may in fact underestimate what might actually occur in a non-study setting. This last point serves to highlight the importance of studying how best to treat older patients with this group of malignancies.

In conclusion, the present study suggests that older patients with metastatic adenocarcinoma of the esophagus, gastroesophageal junction, and stomach derive higher rates of severe toxicity with chemotherapy. Admittedly, age should not be a factor in deciding whether or not to administer chemotherapy, but less toxic cancer treatment regimens should be considered for older patients.

\section{Acknowledgements}

This study was conducted as a collaborative trial of the North Central Cancer Treatment Group and Mayo Clinic and was supported in part by Public Health Service grants: CA-25224, CA-37404, CA-15083, CA-63848, CA-35195, CA-35090, CA-35269, CA-37417, CA-52654, CA-35267, CA-63849, CA-35113, CA-60276, CA-35119, CA-35103, and CA-35431. It was also supported by K24CA131099 awarded to A.J.

\section{References}

1. Blank TO and Bellizzi KM: A gerontologic perspective on cancer and aging. Cancer 112 (Suppl): 2569-2576, 2008. 
2. El-Serag HB: The epidemic of esophageal adenocarcinoma. Gastroenterol Clin North Am 31: 421-440, 2002.

3. Morita M, Egashira A, Yoshida R, et al: Esophagectomy in patients 80 years of age and older with carcinoma of the thoracic esophagus. J Gastroenterol 43: 345-351, 2008.

4. Internullo E, Moons J, Nafteux P, et al: Outcome after esophagectomy for cancer of the esophagus and GEJ in patients aged over 75 years. Eur J Cardiothorac Surg 33: 1096-1104, 2008.

5. Takeuchi S, Ohtsu A, Doi T, et al: A retrospective study of definitive chemoradiotherapy for elderly patients with esophageal cancer. Am J Clin Oncol 30: 607-611, 2007.

6. Ruol A, Portale G, Castoro C, et al: Effects of neoadjuvant therapy on perioperative morbidity in elderly patients undergoing esophagectomy for esophageal cancer. Ann Surg Oncol 14: 3243-3250, 2007

7. Ruol A, Portale G, Castoro C, et al: Management of esophageal cancer in patients aged over 80 years. Eur J Cardiothorac Surg 32: 445-448, 2007.

8. Kim JH, Chung HS, Youn YH, et al: Treatment outcomes of 70 cases of early esophageal carcinoma: 12 years of experience. Dis Esophagus 20: 297-300, 2007.

9. Anderson SE, Minsky BD, Bains M, Hummer A, Kelsen D and Ilson DH: Combined modality chemoradiation in elderly oesophageal cancer patients. Br J Cancer 96: 1823-1827, 2007.

10. Wheatley-Price P, Ding K, Seymour L, Clark GM and Shepherd FA: Erlotinib for advanced non-small cell lung cancer in the elderly: an analysis of the National Cancer Institute of Canada Clinical Trials Group Study BR.21. J Clin Oncol 26: 2350-2357, 2008

11. Sargent DJ, Goldberg RM, Jacobson SD, et al: A pooled analysis of adjuvant chemotherapy for resected colon cancer in elderly patients. N Engl J Med 345: 1091-1097, 2001.

12. Muss HB, Berry DA, Cirrincione C, et al: Toxicity of older and younger patients treated with adjuvant chemotherapy for node-positive breast cancer: the Cancer and Leukemia Group B Experience. J Clin Oncol 25: 3699-3704, 2007.

13. Lipscombe LL, Gomes T, Levesque LE, et al: Thiazolidinediones and cardiovascular outcomes in older patients with diabetes. JAMA 298: 2634-2643, 2007.

14. Hsu J, Fung V, Price M, et al: Medicare beneficiaries' knowledge of Part D prescription drug program benefits and responses to drug costs. JAMA 299: 1929-1936, 2008.

15. Al-Batram SE, Hartmann JT, Probst S, et al: Phase III trial in metastatic gastroesophageal adenocarcinoma with fluorouracil, leucovorin plus either oxaliplatin or cisplatin: a study of the Arbeitsgemeinschaft Internistische Onkolgie. J Clin Oncol 26: $1435-1442,2008$
16. Cunningham D, Starling N, Rao S, et al: Capecitabine and oxaliplatin for advanced esophagogastric cancer. N Engl J Med 358: 36-46, 2008.

17. MacDonald JS, Smalley SR, Benedetti J, et al: Chemoradiotherapy after surgery compared with surgery alone for adenocarcinoma of the stomach or gastroesophageal junction. $\mathrm{N}$ Engl J Med 345: 725-730, 2001

18. Ajani JA, Moiseyenko VM, Tjulandin S, et al: Clinical benefit with docetaxel plus fluorouracil and cisplatin compared with cisplatin and fluorouracil in a phase III trial of advanced gastric or gastroesophageal cancer adenocarcinoma: the V-325 Study Group. J Clin Oncol 25: 3205-3209, 2007.

19. Elliott TE, Moertel CG, Wieand HS, et al: A phase II study of the combinatin of etoposide and cisplatin in the therapy of advanced gastric cancer. Cancer 65: 1491-1494, 1990

20. Rubin J, Gallagher JG, Schroeder G, et al: Phase II trials of f-fluorouracil and leucovorin in patients with metastatic gastric or pancreas carcinoma. Cancer 78: 1888-1891, 1996.

21. Burch PA, Keppen MD, Schroeder G, et al: North Central Cancer Treatment Group phase II study of 5-fluorouracil and high-dose levamisole for gastric and gastroesophageal cancer using survival as the primary end-point of efficacy. Am J Clin Oncol 22: 505-508, 1999.

22. Erlichman C, Goldberg RM, Mahoney MR, et al: A phase II trial of CPT-11 in patients with advanced gastric or gastroesophageal junction adenocarcinoma: a clinical and pharmacodynamic evaluation. A North Central Cancer Treatment Group Study 23: S16, 4026A, 2005.

23. Jatoi A, Tirona MT, Cha SS, et al: A phase II trial of docetaxel and CPT-11 in patients with metastatic adenocarcinoma of the esophagus, gastroesophageal junction, and gastric cardia. Int J Gastrointest Cancer 32: 115-123, 2002.

24. Jatoi A, Murphy BR, Foster NR, et al: Oxaliplatin and capecitabine in patients with metastatic adenocarcinoma of the esophagus, gastroesophageal junction and gastric cardia: a phase II study from the North Central Cancer Treatment Group. Ann Oncol 17: 29-34, 2006.

25. Giordano KF, Jatoi A, Stella PF, et al: Docetaxel and capecitabine in patients with metastatic adenocarcinoma for the stomach and gastroesophageal junction: a phase II study from the North Central Cancer Treatment Group. Ann Oncol 17: 652-656, 2006.

26. Jatoi A, Dakhil SR, Foster NR, et al: Bortezomib, paclitaxel, and carboplatin as a first-line regimen for patients with metastatic esophageal, gastric, and gastroesopheal cancer: phase II results from the North Central Cancer Treatment Group (N044B). J Thorac Oncol 3: 516-520, 2008. 